\title{
Transplantation of Single Mismatch Hematopoietic Stem Cells with Third Party Mesenchymal Stem Cells for Severe Aplastic Anemia: A Case Report and Mini Review
}

\author{
Keni $\mathbf{N}^{1 *}$, Kaynar $\mathbf{L}^{1}$, Ünal $\mathrm{A}^{1}$, Demir $\mathrm{K}^{1}$, Ermiş \\ Turak E' ${ }^{1}$, Gönen $Z^{2}$, Eser $B^{1}$, Şıvgın $S^{1}$ and Çetin \\ $\mathbf{M}^{1}$ \\ ${ }^{1}$ Department of Hematology, Erciyes Transplant Center, \\ Turkey \\ ${ }^{2}$ Genome and Stem Cell Center (GENKOK), Erciyes \\ University, Turkey \\ *Corresponding author: Nermin Keni, Department of \\ Hematology, Erciyes Transplant Center, Kayseri, Turkey
}

Received: March 14, 2017; Accepted: April 19, 2017;

Published: May 10, 2017

\begin{abstract}
While allogeneic hematopoietic stem cells transplantation (allo-HSCT)from HLA-identical siblings has high success rates for aplastic anemia, transplantation from HLA identical or mismatched unrelated donors carries a higher risk of engraftment failure and graft versus host disease (GVHD), remarkably reducing its success rate. A 36 year old woman was diagnosed with severe aplastic anemia and paroxysmal nocturnal hemoglobinuria. Immunosuppressive therapy failed and there was no available HLA compatible family donor. Allo-HSCT was performed using a 9/10 matched unrelated donor with the support of third party mesenchymal stem cells. On patient follow-up, successful engraftment was obtained and neither acute nor chronic graft-versus-host-disease was observed. Mesenchymal stem cells which have immunomodulatory, migratory and regenerative properties may increase the changes of success in unrelated HSCT.
\end{abstract}

Keywords: Mesenchymal stem cells; Hematopoietic stem cells; Paroxysmal nocturnal hemoglobinuria

\section{Introduction}

Mesenchymal stem cells (MSCs) are non- hematopoietic, spindle-shaped fibroblastoid bone marrow progenitor cells. MSCs don't express hematopoietic stem cells markers such as CD34 and CD45. Phenotypically they express CD44, CD73 (SH3/4), CD90, CD146, CD105 (SH2), vimentin, endoglin, SSEA-1 and SSEA-4. They have come to be preferred in clinical use because of their immunosuppressive, immunoregulatory and migratory properties and differentiation capacity for tissues such as muscle, bone, cartilage $[1,2]$.

MSCs are a heterogeneous population of cells containing various stem cells which tend to decrease with increasing age. The main sources of MSCs are bone marrow, cord blood, peripheral blood and adipose tissue [3].

While HLA-I antigens are weakly expressed on the surface of MSCs, HLA-II antigens are not. Therefore MSCs can be used for the treatment of graft-versus-host-disease (GVHD) [4]. MSCs can synthesize cytokines and extracellular matrix proteins. It is though that MSCs show accelerating effect on neutrophil and platelet engraftments in autologous and allogeneic hematopoietic stem cells transplant (allo-HSCT) by supporting the placement, proliferation and differentiation of stem cells with their GM-CSF, G-CSF, SCF and IL-6 secreting properties. Via cytokines MSCs also display immunosuppressive properties by inhibiting the formation and activation of T lymphocytes and proliferation of CD4+ CD25+ T lymphocytes. Thus, MSCs can be used in allo-HSCT to reduce the risk of allograft rejection and GVHD $[5,6]$.

It has been observed that MSCs accelerate the engraftment process and -also decrease the GVHD risk in patients with aplastic anemia (AA) who have a higher risk of primary and secondary graft failure and increased risk of GVHD after allo-HSCT [7,8]. MSCs can help improve tissue toxicity associated with allo-HSCT, by repairing the damaged tissue. MSCs also promise good results for the treatment of GVHD associated with HSCT $[9,10]$.

A successful allo-HSCT was performed on our patient from an HLA- single mismatched unrelated donor, despite the increased risk of engraftment failure and GVHD. No MSC-induced toxicity was observed.

\section{Case Presentation}

Our 36 year old patient was diagnosed with severe aplastic anemia and paroxysmal nocturnal hemoglobinuria $(\mathrm{PNH})$ at another health center in September 2012 (PNH clone rate was: 80\%). Eculizumab was not administered for the treatment because the patient had no history of thrombosis and hemolysis associated with $\mathrm{PNH}$; instead she was treated with cyclosporine and anti-thymocyte globulin (ATG) (horse origin). The patient's situation did not improve

with the ATG treatment containing two doses at an interval of six months. The patient was still unresponsive in the following six month period after the last ATG dose. She had about two units of red blood cell transfusion requirement per month. The patient had to get hospitalization and treatment because of life threatening neutropenic colitis which repeated three times.

A single mismatched HLA-B locus unrelated donor was found for the patient who was unresponsive to immunosuppressive therapy which had been given twice and had no HLA matched related donor. The patient was admitted to our center for allo-HSCT. Her blood
Ann Hematol Oncol - Volume 4 Issue 5 - 2017 ISSN : 2375-7965 | www.austinpublishing group.com Keni et al. (C) All rights are reserved
Citation: Keni N, Kaynar L, Ünal A, Demir K, Ermiş Turak E, Gönen ZB, et al. Transplantation of Single Mismatch Hematopoietic Stem Cells with Third Party Mesenchymal Stem Cells for Severe Aplastic Anemia: A Case Report and Mini Review. Ann Hematol Oncol. 2017; 4(5): 1150 
Table 1: The patient's complete blood count results before and after allo-HSCT.

\begin{tabular}{|l|c|c|c|c|c|}
\hline Date & $\begin{array}{c}\text { Wbc } \\
\left(10^{3} / \mu \mathrm{L}\right)\end{array}$ & $\begin{array}{c}\mathrm{Neu} \\
\left(10^{3} / \mu \mathrm{L}\right)\end{array}$ & $\begin{array}{c}\mathrm{Hb} \\
(\mathrm{gr} / \mathrm{dl})\end{array}$ & $\begin{array}{c}\mathrm{Plt} \\
\left(10^{3} / \mu \mathrm{L}\right)\end{array}$ & $\begin{array}{c}\text { Ret } \\
\left(10^{3} / \mu \mathrm{L}\right)\end{array}$ \\
\hline $\begin{array}{l}\text { 26 May 2014 } \\
\text { (before allo-HSCT) }\end{array}$ & 2270 & 500 & 5 & 20.000 & 16.000 \\
\hline $\begin{array}{l}\text { 6 January 2016 } \\
\text { (+270 day after allo-HSCT) }\end{array}$ & 4100 & 1400 & 12.8 & 105.000 & - \\
\hline
\end{tabular}

Wbc: Leukocytes; Neu: Neutrophil; Hb: Hemoglobin; Plt: Platelets; Ret: Reticulocytes; Allo-HSCT: Allogeneic Hematopoietic Stem Cells Transplantation

count and peripheral smear were compatible with sever aplastic anemia at admission (Table 1).

Allo-HSCT from the 9/10 HLA-matched donor was performed with conditioning regime consisting offludarabine, cyclophosphamide and ATG (fludarabine $180 \mathrm{mg} / \mathrm{m}^{2}$, cyclophosphamide $120 \mathrm{mg} / \mathrm{kg} /$ day, mesna $60 \mathrm{mg} / \mathrm{kg} /$ day, ATG $15 \mathrm{mg} / \mathrm{kg} /$ day) regime for the preparation protocol. For GVHD prophylaxis a low dose of methotrexate and cyclosporin were administered. Third party MSCs $\left(1 \times 10^{6}\right.$ cells $\left./ \mathrm{kg}\right)$ was administered on the allo-HSCT day. No adverse effects occurred during the MSCs infusion. We received permission from the Ministry of Health for the administering of MSCs.

The patient achieved neutrophil engraftment on day 25 and platelet engraftment on day 24. During follow-up, febrile neutropenia was occurred on day 14 post allo-HSCT and piperacillin/tazobactam was started at a dose of $4 \times 4.5 \mathrm{gr} /$ day. On day 21 , patient was at a stable state with clinic and laboratory examinations and the antibiotherapy was stopped. On day 28 prophylactic intravenous immunoglobulin (IVIG) was administered at a dose of $0.4 \mathrm{gr} / \mathrm{kg}$. Neither acute nor chronic GVHD was observed in the patient. She was discharged with recommendations for her future well-being on day 30 .

We continue to monitor the patient's situation; she is in remission and has no PNH clone. Chimerism was observed $98.4 \%$ one month after the transplantation. Patient's flow cytometry results related to PNH before and after HSCT are shown in Figure1A,1B. The main complete blood count results following the allo-HSCT are shown in Table 1.

\section{Discussion}

MSCs have tissue restorative, regenerative, migratory, immunosuppressive and immunomodulatory properties. After intravenous infusion MSCs usually reach the bone marrow and have a tendency to settle there. If there is an inflammation they can migrate to that area and settle [11].

MSCs show their effects via immunosuppression: $\mathrm{T}$ cell suppression, inhibition of $\mathrm{B}$ cells and dendritic cells derived from
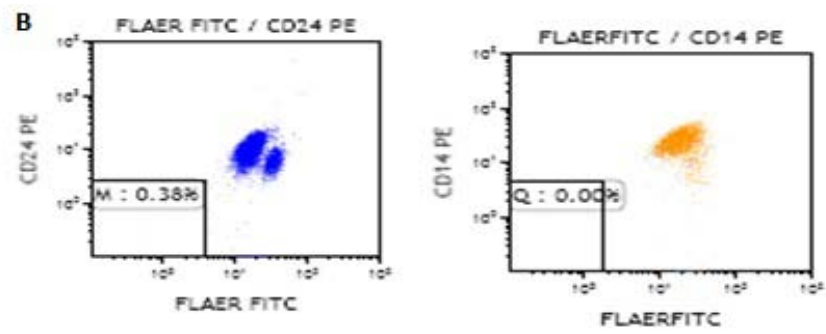

Figure 1B: Patient's flow cytometry results after allo-HSCT.

monocytes as well as growth of hematopoietic stem cells and their precursors and increase in vitro megakaryocytic and platelet formation $[12,13]$. They help the expression of extracellular matrix proteins and adhesion molecules which provide nest for the hematopoietic system through their various hematopoietic growth factor products.

MSCs contribute to proliferation, differentiation and settlement of stem cells after autologous and allo-HSCT by their cytokines secretion properties such as GM-CSF, G-CSF, SCF and IL-6. Therefore MSCs are considered to have accelerating effect on neutrophil and platelet engraftment. In studies it has been shown to decrease transfusion requirements and also reduce the frequency of bacterial and fungal infections owing to rapid engraftment with the support of MSCs, MSCs also reduce the increased risk of allograft rejection and GVHD in allo-HSCT through T cell suppression.

MSCs can reduce tissue damage through its restorative properties when administered concurrently with chemotherapy. With the support of MSCs successful results were obtained for patients with hemorrhagic cystitis whose treatment are complicated by colon perforation [9]. Some health centers think that MSCs may prove insufficient to avoid toxicity mediated by cytotoxic T cells, therefore it has been suggested that MSCs must be combined with systemic immunosuppressive therapy to provide adequate $\mathrm{T}$ cell suppression [14]. It has been observed that the risk of a leukemic relapse after stem cells transplantation can be reduced with the anti-tumor effect of GVHD in leukemic patients, especially with chronic GVHD [15]. Studies suggest that MSCs may increase the risk of a leukemic relapse despite the reduction of the GVHD risk.

Immunomodulatory effects of MSCs against allo-antigens brought forward consideration the idea that MSCs can be used for solid organ allograft rejections such as kidney, heart, liver and bowel. It has been discovered in allograft studies conducted with rats that MSCs immigrate to the area of rejection and settle there
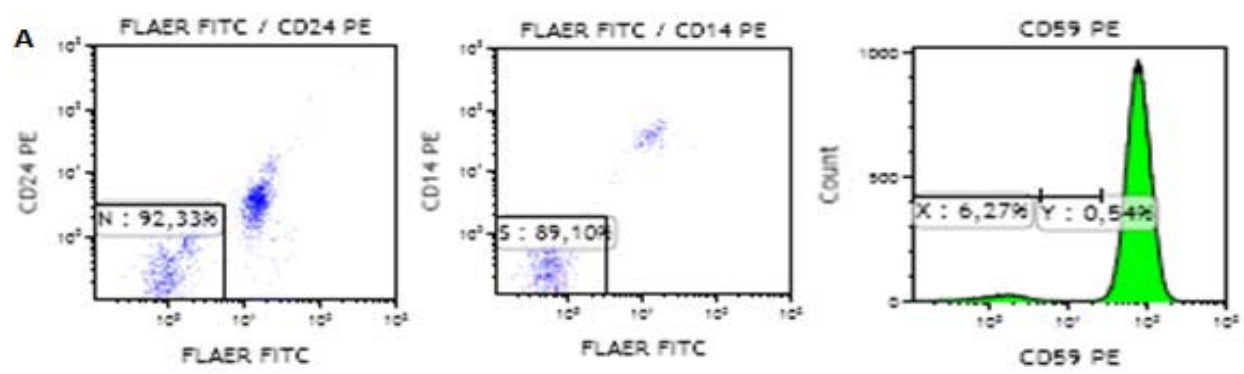

Figure 1A: Patient's flow cytometry results before allo-HSCT. 
after infusion [16]. MSCs are found to have improved the intestinal damage in studies concerning inflammatory bowel disease [17] MSCs have become one of the most preferred treatment methods with their immunomodulatory and tissue restorative effects in pulmonary fibrosis, myocardial infarction, cardiomyopathy, renal ischemia, cartilage destruction and various autoimmune diseases such as systemic lupus erythematosus and scleroderma. We need more studies to have a better understanding of the biology of MSCs, to illuminate their benefits and drawbacks and to determine the right dose and the right time of use for the treatment of diseases and complications.

Today, hematopoietic stem cells transplantations from unrelated donors with support of the MSCs are regarded as a promising treatment method to reduce the risk of transplant complications such as graft failure and GVHD.

\section{References}

1. Anjos-Afonso F, Bonnet D. Nonhematopoietic/endothelial SSEA-1+ cells define the primitive progenitors in the adult murine bone marrow mesenchymal compartment. Blood. 2007; 109:1298-1306.

2. Gang EJ, Bosnakovski D, Figueiredo CA, Visser JW, Perlingeiro RC. SSEA4 identifies mesenchymal stem cells from bone marrow. Blood. 2007; 109: 1743-1751.

3. Campagnoli C, Roberts IA, Kumar S, Bennett PR, Bellantuono I, Fisk NM. Identification of mesenchymal stem/progenitor cells in human first-trimester fetal blood, liver and bone marrow. Blood. 2001; 98: 2396-2402.

4. Le Blanc K, Ringdén O. Immunomodulation by mesenchymal stem cells and clinical experience. J Intern Med. 2007; 262: 509-525.

5. Pelagiadis I, Dimitriou H, Kalmanti M. Biologic characteristics of mesenchyma stromal cells and their clinical applications in pediatric patients $\mathrm{J}$ Pediatr Hematol Oncol. 2008; 30: 301-309.

6. Le Blanc K, Samuelsson H, Gustafsson B, Remberger M, Sundberg B Arvidson J, et al. Transplantation of mesenchymal stem cells to enhance engraftment of hematopoietic stem cells. Leukemia. 2007; 21: 1733-1738.

7. Fang B, Ning Li, Song $\mathrm{Y}$, Li J, Zhao RC, Ma Y. Cotransplantation of haploidentical mesenchymal stem cells to enhance engraftment of hematopoieticstem cells and to reduce the risk of graft failure in two children with severe aplastic anemia. Pediatr Transplant. 2008.
8. Foillard L, Bensidhoum M, Bories D, Bonte H, Lopez M, Moseley AM, et al. Engraftment of allogenic mesenchymal stem cells in the bone marrow of a patient with severe idiopathic aplastic anemia improves stroma. Leukemia. 2003; 17: 474-476.

9. Ringden O, Uzunel M, Sundberg B, Lönnies L, Nava S, Gustafsson J, et al. Tissue repair using allogenic mesenchymal stem cells for hemorrhagic cystitis, pneumomediastinum and perforated colon. Leukemia. 2007; 21: 2271-2276

10. Ringdén $\mathrm{O}$, Uzunel M, Rasmusson I, Remberger M, Sundberg $B$, Lönnies $H$, et al. Mesenchymal stem cells for treatment of therapy-resistant graft-versushost disease. Transplantation. 2006; 81: 1390-1397.

11. Chen FM, Wu LA, Zhang M, Zhang R, Sun HH. Homing of endogenous stem/progenitor cells for in situ tissue regeneration: promises, strategies and translational perspectives. Biomaterials. 2011; 32: 3189-3209.

12. Yagi H, Soto-Gutierrez A, Parekkadan B, Kitagawa Y, Tompkins RG, Kobayashi $\mathrm{N}$, et al. Mesenchymal stem cells: mechanisms of immunomodulation and homing. Cell Transplant. 2010; 19: 337-345.

13. Corcione A, Benvenuto F, Ferretti E, Giunti D, Cappiello V, Cazzanti F, et al. Human mesenchymal stem cells modulate B-cell functions. Blood. 2006; 107: 367-372.

14. Rasmusson I, Ringdén O, Sundberg B, Le Blanc K. Mesenchymal stem cells inhibit the formation of cytotoxic $\mathrm{T}$ lymphocytes, but not activated cytotoxic T lymphocytes or natural killer cells. Transplantation. 2003; 76: 1208-1213.

15. Ringden O, Labopin M, Gluckman E, Reiffers J, Vernant JP, Jouet JP, et al. Graft-versus-leukemia effect in allogeneic marrow transplant recipients with acute leukemia is maintained using cyclosporin A combined with methotrexate as prophylaxis. Akute Leukemia Working Party of the European Group for Blood and Marrow Transplantation. Bone Marrow Transplant 1996; 18: 921-929.

16. Wu GD, Nolta JA, Jin YS, Barr ML, Yu H, Starnes VA, et al. Migration of mesenchymal stem cells to heart allografts during chronic rejection. Transplantation. 2003; 75: 679-685.

17. Manieri NA, Stappenbeck TS. Mesenchymal stem cell therapy of intestinal disease: are their effects systemic or localized? Curr Opin Gastroenterol. 2011; 27 : 119-1124.

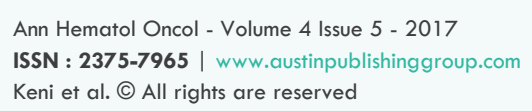
and Mini Review. Ann Hematol Oncol. 2017; 4(5): 1150. 